\title{
Hui Chinese
}

National Cancer Institute

\section{Source}

National Cancer Institute. Hui Chinese. NCI Thesaurus. Code C158160.

A Chinese person from the Hui (including Utsuls of Hainan, descended from Cham refugees) ethnic group. 